\title{
Percepções biopedagógicas da dança em crianças com deficiência visual
}

Biopedagogical perceptions of dance in children with visual impairment Percepciones biopedagógicas de la danza en niños con discapacidad visual

Recebido: 18/05/2020 | Revisado: 19/05/2020 | Aceito: 25/05/2020 | Publicado: 04/06/2020

\section{Nilson Vieira Pinto}

ORCID: https://orcid.org/0000-0001-6548-8586

Instituto Federal de Educação, Ciência e Tecnologia do Ceará, Brasil

E-mail: nilsonvieira@ifce.edu.br

\section{Resumo}

Objetivo: avaliar as percepções biopedagógicas da aplicação da dança em crianças com deficiência visual a partir do olhar sensível da família. Metodologia: trata-se de um estudo de campo, com abordagem qualitativa descritiva, que avaliou a percepção do desempenho biopedagógico nos aspectos afetivo-emocionais, cognitivos, psicomotores e socioculturais, através da aplicação de questionário objetivo a 23 pais de crianças com deficiência visual,

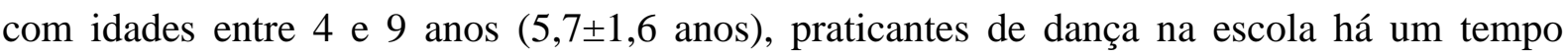
mínimo de três meses. Resultados: Todos os pais perceberam a ampliação das dimensões afetivo-emocional e psicomotora em seus filhos, entretanto o desempenho da dimensão cognitiva não foi percebido por dois $(8,7 \%)$ e a sociocultural por três $(13 \%)$ pais. A interação entre os aspectos cognitivo e social foi discutida frente à possíveis relações etiológicas destes resultados. Conclusão: A dança possibilitou o desempenho dos aspectos biopedagógicos avaliados. Essas relações de desempenho são influenciadas pela interação entre a criança, seus pais e o mundo.

Palavras-chave: Dança; Deficiência visual; Relações familiares; Educação; Ensino.

\footnotetext{
Abstract

Objective: to evaluate the bio-pedagogical perceptions of the application of dance in children with visual impairment from the sensitive perspective of the family. Methodology: this is a field study, with a descriptive qualitative approach, which evaluated the perception of biopedagogical performance in the affective-emotional, cognitive, psychomotor and socio-
} 
cultural aspects, through the application of an objective questionnaire to 23 parents of children with visual impairment, aged between 4 and 9 years $(5.7 \pm 1.6$ years), dance practitioners at school for a minimum of three months. Results: All parents noticed the expansion of the affective-emotional and psychomotor dimensions in their children, however the performance of the cognitive dimension was not perceived by two $(8.7 \%)$ and the sociocultural dimension by three (13\%) parents. The interaction between the cognitive and social aspects was discussed in view of the possible etiological relationships of these results. Conclusion: The dance enabled the performance of the biopedagogical aspects evaluated. These performance relationships are influenced by the interaction between the child, his parents and the world.

Keywords: Dance; Visual impairment; Family relations; Education; Teaching.

\section{Resumen}

Objetivo: evaluar las percepciones biopedagógicas de la aplicación de la danza en niños con discapacidad visual desde la perspectiva sensible de la familia. Metodología: este es un estudio de campo, con un enfoque cualitativo descriptivo, que evaluó la percepción del desempeño biopedagógico en los aspectos afectivo-emocional, cognitivo, psicomotor y sociocultural, mediante la aplicación de un cuestionario objetivo a 23 padres de niños con discapacidad visual. con edades comprendidas entre 4 y 9 años (5,7 \pm 1,6 años), practicantes de baile en la escuela durante un mínimo de tres meses. Resultados: Todos los padres notaron la expansión de las dimensiones afectivo-emocionales y psicomotoras en sus hijos, sin embargo, el desempeño de la dimensión cognitiva no fue percibido por dos $(8.7 \%)$ y la dimensión sociocultural por tres (13\%) padres. La interacción entre los aspectos cognitivos y sociales se discutió en vista de las posibles relaciones etiológicas de estos resultados. Conclusión: El baile permitió la realización de los aspectos biopedagógicos evaluados. Estas relaciones de rendimiento están influenciadas por la interacción entre el niño, sus padres y el mundo.

Palabras clave: Baile; Discapacidad visual; Relaciones familiares; Educación; Enseñanza.

\section{Introdução}

A dança é instrumento de linguagem do qual se utiliza do movimento corporal dentro do espaço e do tempo para expressar estética e afetivamente seus versos (Delmiro e Pinto, 2020). Durante séculos, se desenvolveu profissionalmente em um corpo branco, magro, 
atlético e não deficiente (Albarran, Silva \& Cruz, 2018), contudo, nas últimas décadas vem se discutindo os potenciais biopedagógicos que envolvem o ensino da dança inserida em um perspectiva educativa e inclusiva, estabelecendo seu papel formativo transcendente ao ato performático/artístico.

Cazé \& Oliveira (2008) pontuam que o corpo cego se desenvolve através da interação com as outras vias sensorais, sendo a visão a única que se diferencia do corpo sem deficiência. Acrescentam que o processo de aprendizagem da dança se estabelece pela interação das percepções e sensações oriundas do movimento corporal, sem necessariamente ser o espelho de uma representação visual.

Albarran, Silva \& Cruz, (2018) em seu estudo de revisão, investigaram vinte anos de produção acadêmica brasileira sobre a dança em pessoas com deficiência visual, pontuando estudos que apontavam aspectos positivos no desenvolvimento da consciência corporal, no aumento da mobilidade e da sensibilidade interpessoal, no desempenho do equilíbrio, da força e da flexibilidade, na melhora da autoestima e da autoconfiança.

Os estudos são realizados predominantemente em adultos jovens e com ênfase na profissionalização do bailarino. Pouco se tem explorado as perspectivas biopedagógicas, onde a ação pedagógica está refletida em seu caminhar biológico, desenvolvidas através da prática regular de dança educativa em crianças com deficiência visual.

Mesmo diante do Plano de Desenvolvimento da Educação - PDE, o qual aponta a Política Nacional de Educação Especial na Perspectiva da Educação Inclusiva, evidencia-se a dificuldade de se desenvolver conteúdos acessíveis e inclusivos (Peixoto e da Silva, 2018). Exercitar o fazer pedagógico reflexivo é identificar os caminhos linguísticos capazes de estabelecer relações entre a criança e seus elementos constitutivos como o espaço, o tempo e o ritmo, provocando relações de interação entre os sentidos e as práticas.

Pinto e Lima (2019) comentam que os diversos estímulos sensoriais despertados na criança por intermédio de suas relações familiares são fundamentais para estabelecer alicerces sensório-motores no despertar educativo do ensino da dança infantil. Estes estímulos são iniciados na família e ampliados na escola, devendo sempre permitir interações entre os sujeitos educacionais.

Assim, a apropriação da dança na infância deve explorar todas as possibilidades sensoriais e motoras buscando ampliar as relações entre os conhecimentos da cultura corporal do movimento e os sujeitos da aprendizagem e assim, expandir as dimensões afetivas, cognitivas, motoras e socioculturais destas crianças.

Diante disso, este estudo veio avaliar as percepções biopedagógicas da aplicação da 
dança em crianças com deficiência visual a partir do olhar sensível da família.

\section{Metodologia}

Trata-se de um estudo de campo, com abordagem qualitativa descritiva (Pereira et al., 2018), desenvolvido por um projeto social vinculado a uma escola de assistência a crianças com deficiência visual em Fortaleza, Ceará, Brasil.

Este projeto social desenvolve inúmeras atividades esportivas para todo o publico desta escola, em especial, a dança para as crianças com deficiência visual, que vivenciam duas aulas por semana, com duração média de 50 minutos, através de atividades lúdicas e de ampla exploração sensorial.

A amostra foi composta por 23 pais de crianças com idades entre 4 e 9 anos $(5,7 \pm 1,6$ anos) que participassem regularmente das aulas de dança desenvolvidas nesta escola há um tempo mínimo de três meses.

Todos os pais formam convidados a participar voluntariamente deste estudo, sendo asseguradas todas as garantias estabelecidas pelas normas que regulamentam a pesquisa em seres humanos, do Conselho Nacional de Saúde - Ministério da Saúde, Resolução No 466/2012. Foram excluídos da análise, os questionários de investigação que estivessem com o preenchimento incompleto ou de crianças com assiduidade inferior a $75 \%$ das aulas nos últimos três meses.

A coleta dos dados se deu através da aplicação de um questionário de investigação da percepção familiar (elaborado pelo autor), contendo 15 perguntas objetivas direcionadas as dimensões afetivo-emocionais, cognitivas, psicomotoras e socioculturais e suas relações com a prática da dança educativa.

A dimensão afetivo-emocional investigava o desempenho da autoestima, da autoconfiança e do despertar de sentimentos; a cognitiva, investigava as relações com a memória, o raciocínio e o desempenho da linguagem; a psicomotora, o desempenho da coordenação motora (global e fina), da organização temporal e espacial e da lateralidade; e a sociocultural, a interação com os demais colegas da turma e com a família, descobertas culturais e possíveis mudanças nos hábitos diários.

A análise dos dados se deu inicialmente pela tabulação dos resultados em uma planilha em excel (windows office 2016), expressos em valores absolutos e em percentuais e posterior análise crítica fundamentada. 


\section{Resultados e Discussão}

O desempenho pluridimensional promovido pela prática regular de uma dança educativa de ampla abordagem biopedagógica foi avaliado quanto as suas possibilidades afetivo-emocionais, cognitivas, psicomotoras e socioculturais sob a ótica sensível e atenta de seus familiares.

Na dimensão afetiva-emocional todos os pais pontuaram uma melhor autoconfiança e autoestima dos seus filhos com a prática regular de dança na escola. Não obstante, todos reconheceram a vitalidade de sentimentos através da motivação e da alegria das crianças ao retornar das aulas e na expressividade do cotidiano doméstico.

Segundo Motta, Motta \& Liberali (2012) a autoestima é constituída pela autoimagem associada ao autoconceito, sendo este último desenvolvido a partir de estímulos e informações estabelecidas pelo meio social em que vive. Para Ferreira, Villela e Carvalho (2010) a autoestima e o autoconceito são construtos da personalidade, onde o autoconceito refere-se ao que cada um pensa que é e a autoestima a habilidade pessoal em enfrentar ou se adequar aos desafios da vida.

Toda criança encontra-se em um processo de elaboração da sua personalidade, consequentemente no ato de se estabelecer o seu autoconceito, fomentado pelas relações interpessoais, as quais consequentemente motivarão o desempenho da autoestima. Desta forma, a ampla exploração sensorial vivenciada nas aulas de dança na escola tem influenciado positivamente na formação do autoconceito e da autoestima dessas crianças. É interessante destacar que a autoimagem aqui desenvolvida, em nada se refere ao simples olhar estético no espelho e sim à diversas sedimentações afetivo-emocionais que constituem a "real" autoestima e fazem com que esta criança se sinta, de fato, incluída em sociedade.

Na dimensão cognitiva, 21(91,3\%) pais perceberam uma melhora na memória e no raciocínio lógico de seus filhos, caracterizado pela melhor apreensão das palavras, respostas cotidianas na resolutividade de novos problemas e no melhor rendimento escolar.

Lima Muniz \& Ribeiro (2010) afirmam que o movimento se relaciona com o desenvolvimento cognitivo, por permitir a integração das vias sensoriais periféricas e centrais com o sistema motor. Wachowicz (2010) comenta que a cognição envolve os mesmos mecanismos da percepção, dependentes da reunião, interpretação e organização dos estímulos sensoriais.

Os processos biopedagógicos desenvolvidos na dança educativa na infância se utilizam de corpo, gestos e movimentos associados às diversas experiências sensoriais, 
permitindo assim uma melhor interação sináptica e consequente resposta cognitiva. Esses processos podem ser reconhecidos através dos jogos de mímicas, uso de linguagens associativas, ampliação de repertório rítmico e das demais atividades rítmicas e expressivas desenvolvidas em sala de aula.

Vale comentar que dois $(8,7 \%)$ pais não perceberam uma melhora dos aspectos cognitivos pontuados no questionário. $\mathrm{O}$ trato objetivo deste estudo não permite estabelecer com clareza esta percepção, todavia pode ser ponderado que aspectos pessoais ou mesmo, outras deficiências possam justificar esta relação.

$\mathrm{Na}$ avaliação da dimensão psicomotora, todos os pais afirmaram ter percebido uma melhora na coordenação motora global, caracterizada pela execução de movimentos complexos mais harmônicos e na facilidade de executar movimentos de grande solicitação neuromuscular; na coordenação motora fina, assinalando a melhora na ação de movimentos de maior precisão como a escrita e a preensão, melhora da postura e do equilíbrio; bem como na organização espaço-temporal, melhorando as noções de direção (cima, baixo, à frente, atrás e ao lado), de distância (longe, perto, longo e comprido), de ritmo (rápido e lento) e na melhora na lateralidade.

Pfeifer \& Defina (2008) avaliaram o desempenho psicomotor de crianças com deficiência visual inseridas em um programa de intervenção, que utilizou a dança como recurso terapêutico ocupacional. Este estudo evidenciou a prevenção de déficits psicomotores e a aquisição da coordenação motora global, da orientação espacial e temporal.

Meereis et al., (2011) comentam em seu estudo de revisão que durante o desenvolvimento psicomotor a organização da ação está relacionada aos sistemas visual e proprioceptivo que elabora, organiza e qualifica as experiências sensório-motoras. Em uma criança com deficiência visual, a necessidade de exploração dos demais sentidos é essencial para possibilitar que essa criança amplie seus sentidos, explore melhor o ambiente e desenvolva a segurança necessária para o desempenho psicomotor. Esta revisão descreve ainda, alguns estudos que caracterizam o comprometimento do desenvolvimento psicomotor decorrente da deficiência visual quando comparados a crianças com visão normal.

Nossos achados reverberam uma caracterização positiva nos aspectos psicomotores avaliados, mesmo não tendo comparado essas respostas entre crianças com visão normal. Acredita-se que estes resultados estejam relacionados à diversidade de estímulos sensoriais desenvolvidos nas aulas de dança educativa, com ênfase aos estímulos auditivos e tácteis, imprescindíveis no desempenho dos processos biopedagógicos. 
A linguagem corporal através da dança se utiliza de movimentos complexos inseridos em ampla exploração da lateralidade, do espaço e do tempo, em distintas direções, velocidades, intensidades, de forma repetitiva, sucessiva e espontânea, fazendo com que o desempenho psicomotor seja uma consequência natural de sua prática.

Em uma análise da dimensão sociocultural pode-se identificar que todos os pais perceberam novas descobertas culturais em seus filhos, caracterizadas no discurso ampliado do repertório musical, dos costumes e tradições entre os povos e dos tipos de dança discutidos em aula, bem como a percepção na mudança voltada a adoção de um estilo de vida mais saudável. Todavia, $3(13 \%)$ pais não perceberam uma melhora na interação entre os seus filhos e os seus colegas de turma, bem como com seus familiares.

É natural pensarmos em processos de socialização oriundos da prática regular de exercícios físicos, especialmente nas atividades coletivas como a dança. Geralmente os estudos apontam a dança como uma ferramenta importante de sociabilização de idosos (Checom e Gomes, 2015; Silva e de Almeida Buriti, 2012) e pouco se tem explorado os processos de sociabilização em crianças e jovens através das atividades rítmicas e expressivas. Independente disso, os processos biopedagógicos desempenhados de forma coletiva tendem a permitir uma melhor aproximação de seus atores.

De acordo com de Castro Monteiro e Gaspar, (2016), a interação social, quer seja em sala de aula ou em casa, retrata as experiências emocionais consigo e com o outro estabelecendo uma dinâmica entre os níveis de consciência, de cognição e emoção. Neste artigo, os autores citam a ótica biológica de Buck (1999) a qual propõe uma taxionomia de afetos que envolvem as relações sociais (orgulho, culpa, vergonha, pena, desdém, ciúme e inveja); cognitivas (interesse, desinteresse, curiosidade e surpresa) e morais (entusiasmo e indignação).

Diante disso, a percepção dos pais ao pontuar que seus filhos não ampliaram suas relações sociais pode estar relacionada a algum fator desencadeador presente na taxonomia de afetos descrita por Buck. Nesta trajetória, é interessante perceber que o resultado identificado na dimensão sociocultural se assemelha a dimensão cognitiva, estabelecendo, portanto, possíveis relações entre o desempenho cognitivo e a interação social destas crianças, que possam ter sido ocasionadas por interesse ou desinteresse, por exemplo.

Essa integração cognitivo-social merece ser mais bem avaliada sob uma luz dialógica promovida entre professor-aluno-família, observando quais delimitações cognitivas ou sociais estão em estase pedagógica e necessitam de suporte educacional. 


\section{Considerações Finais}

A dança na escola, especialmente na infância, através de sua ação pedagógica, deve explorar uma diversidade pluridimensional de estímulos sensoriais.

O uso do corpo, de gestos e de todas as possibilidades de movimento individual e coletivo, pode desenvolver não somente o ser biológico como melhorar as suas relações com o mundo.

O dançar se desenvolve através da interação de percepções intrínsecas e extrínsecas originadas a partir dos estímulos sensoriais em conexão com o movimento corporal, onde o sentido visual é apenas um aspecto dentro desta vastidão de possibilidades biopedagógicas.

Torna-se importante frisar que a criança, é um ser em constante elaboração afetiva, emocional, cognitiva, psicomotora e sociocultural, independente de suas possíveis deficiências e que quando estimuladas fazem com que esta se desenvolva de forma humana, social, artística e inclusiva.

O emprego da propriocepção tátil, dos estímulos auditivos diversos, a escolha do repertório, o uso de linguagens associativas, a exploração da organização espaço-temporal, da lateralidade, dos gestos e movimentos, a exploração verbal dos conceitos e procedimentos em dança e do compartilhamento das experiências com os atores dançantes, promovem o aprimoramento afetivo-emocional, cognitivo, psicomotor e sociocultural em crianças com deficiência visual. Este aprimoramento ocorre através de uma constante conexão entre todos esses fatores biopedagógicos que são assimilados de forma natural, contínua e progressiva.

É valioso perceber que esse processo não é perfeito e concluso. Não é algo garantido. É um produto das relações interacionais entre a criança, seus pais, o professor de dança e o mundo.

Trata-se de um processo iniciado ainda gestacional, com os primeiros estímulos fraternos e constantemente intermediado pelas relações sociais, cognitivas e morais que podem influenciar no desempenho dessas dimensões biopedagógicas.

A investigação ampliada dessas relações sociais, cognitivas e morais entre a criança, seus familiares e a escola podem fundamentar uma maior compreensão dos processos educativos necessários a uma formação inclusiva.

Novos estudos que abordem diferentes estratégias metodológicas do ensino da dança, possibilitando a inserção dos pais neste contexto pedagógico, pode ser um ponto de partida. 


\section{Referências}

Albarran PAO, Silva DNH \& Cruz EAPS (2018). A dança e as pessoas com deficiência visual: Uma análise de vinte anos de produção acadêmica brasileira. Revista de Ciências Humanas, 52, 1-21.

Castro Monteiro IC \& Gaspar A (2016). Um estudo sobre as emoções no contexto das interações sociais em sala de aula. Investigações em Ensino de Ciências, 12(1), 71-84.

Cazé CMDJO \& Silva Oliveira A (2008). Dança além da visão: possibilidades do corpo cego. Pensar a prática, 11(3), 293-3.

Checom DDC \& Gomes GC (2015). A influência da dança na melhoria da qualidade de vida do idoso. Revista Uningá Review, 24(2).

Ferreira SA, Villela WV \& Carvalho R (2010). Dança na Escola: uma contribuição para a promoção de saúde de crianças e adolescentes. Investigação, 10.

Lima PFR, Pinto NV \& Martins RA. (2020). Inclusão no ensino da dança na escola. Research, Society and Development, 9(2), 40.

Lima Muniz M \& Ribeiro MM (2012). Aspectos cognitivos e invenção na improvisação teatral e sua influência na criação de movimentos expressivos em dança. Lamparina-Revista de Ensino de Artes Cênicas, 1(1), 33-41.

Meereis ECW, Lemos LFC, Pranke GI, Alves RF, Teixeira CS \& Mota CB (2011). Deficiência visual: uma revisão focada no equilíbrio postural, desenvolvimento psicomotor e intervenções. Revista Brasileira de Ciência e Movimento, 19(1), 108-13.

Motta MAM, Motta SM \& Liberali R (2012). A motivação e a autoestima de adolescentes em um projeto de dança. Revista Mackenzie de Educação Física e Esporte, 11(2).

Peixoto ERB \& da Silva LHO (2018). Regimes de interação em práticas de inclusão de deficientes visuais. A Cor das Letras, 18(3), 222-40. 
Pereira AS et al (2018). Metodologia da pesquisa científica. [e-book]. Santa Maria. Ed. UAB/NTE/UFSM. Disponível em: <https://repositorio.ufsm.br/bitstream/handle/1/15824/ Lic_Computacao_Metodologia-Pesquisa-Cientifica.pdf?sequence=1> Acesso em 31 mar 2020

Pfeifer LI \& Defina RAA (2008). Dança como recurso terapêutico ocupacional junto a crianças com deficiência visual.

Pinto NV \& Lima PRF (2019). Pressupostos teórico-pedagógicos da iniciação rítmica nas aulas de dança. Holos, 5, 1-12.

Santos Delmiro A \& Pinto NV (2020). Evaluation of flexibility in jazz ballerines submitted to the proprioceptive neuromuscular facilitation method. Research, Society and Development, 9(6), 146963568.

Silva GB \& Almeida Buriti M (2012). Influência da dança no aspecto biopsicossocial do idoso. Revista Kairós: Gerontologia, 15(1), 177-92.

Wachowicz F (2010). Os processos cognitivos de atenção e percepção: Suas relações com a execução, a observação e o aprendizado na dança. Anais ABRACE, 11(1).

\section{Porcentagem de contribuição de cada autor no manuscrito}

Nilson Vieira Pinto - 100\% 